\title{
UNA AMÉRICA LATINA INCÓMODA EN UNA GLOBALIZACIÓN INCONFORTABLE
}

\author{
Ernesto Ottone \\ Universidad Diego Portales
}

\begin{abstract}
RESUMEN: Si se mira el crecimiento económico o el estado del campo social y político, las tendencias actuales no auguran un buen futuro para las democracias del mundo, y son especialmente poco auspiciosas para América Latina. Este ensayo da cuenta de las principales tensiones en la región y pone el foco en las que debieran ser las prioridades del trabajo político de largo plazo.

Palabras Clave: Crecimiento, América Latina, populismo, aspiraciones, desigualdad.
\end{abstract}

\section{LATIN AMERICA UNCOMFORTABLE IN AN AWKWARD GLOBALIZATION}

ABSTRACT: If one looks at economic growth or social and political status, current trends do not foresee a good future for the world's democracies, and are especially gloomy for Latin America. This essay describes the main tensions in the region and focuses on what longterm political priorities should be.

Keywords: Growth, Latin America, Populism, Aspirations, Inequality.

Ernesto Ottone. Sociólogo y doctor en ciencias políticas, Universidad de París III, La Sorbonne Nouvelle. Fue Director de Análisis Estratégico de la Presidencia, durante el gobierno de Ricardo Lagos (2000-2006). Hoy es profesor titular en la Universidad Diego Portales y profesor adjunto en la Universidad de Chile. Email: ernesto.ottone@udp.cl 
S e ha hablado de la fase actual de la globalización como de una campo económico, social y político. Los desarrollos científicos y tecnológicos que siguen su tenaz camino, si bien logran elevar la esperanza de vida, la instantaneidad en las comunicaciones y las diversas modificaciones en las formas de vida a nivel planetario, no resuelven por sí mismos las incertidumbres y problemas, desigualdades y conflictos que marcan la convivencia de nuestras sociedades.

Las perspectivas de crecimiento de la economía mundial no parecen ser brillantes. ¿Será cierto que los impactos de la innovación tecnológica tenderán a ser menores en productividad en el largo plazo? ${ }^{2}$ ¿Debemos acostumbrarnos a pensar que las cifras de crecimiento del siglo XX fueron más bien la excepción en la historia de la economía mundial y que volveremos a promedios bajos, quizás entre 1 y 3 por ciento en el largo plazo?

Si eso fuera así, querría decir que el crecimiento seguirá siendo relativamente alto en los países emergentes sólo mientras den alcance a los países que van adelante en el desarrollo, en la punta tecnológica, y que una vez alcanzado ese punto, los emergentes se unirán al crecimiento lento.

En ese caso, el mundo deberá afrontar con más dificultades los temas globales como el cambio climático, los movimientos dramáticos en la distribución de la población, el envejecimiento y la tendencia general al descenso del crecimiento poblacional en el largo plazo.

¿Puede un mundo destinado a un desarrollo de más lentitud y más riesgos permanecer marcado por la ausencia de gobernanza global, el predominio de conflictos diversos y asimetrías sociales perdurables?

Desde el punto de vista de la razón, todo indica la urgencia de cambios en la convivencia global para administrar un porvenir muy incierto. Pero bien sabemos que la razón juega un papel sólo parcial en la toma de decisiones políticas.

${ }^{1}$ Daniel Cohen, Homo economicus, proféte (egaré) des temps nouveaux (París: Albin Michel, 2012).

${ }^{2}$ Thomas Piketty, Le capital au XXI siècle (París: Seuil, 2013). 


\section{LOS RASGOS DEL CORTO PLAZO}

Repasar las proyecciones económicas que se manifiestan en el corto plazo sólo es útil para vincularlas a tendencias más largas, para ver si son señales del futuro que tiende a dibujarse o sólo son fruto de coyunturas destinadas a desaparecer.

Naturalmente, estas proyecciones cambian, de acuerdo a las metodologías usadas por los organismos que las llevan a cabo, pero no sus trazos gruesos. ${ }^{3}$

El crecimiento mundial presenta rasgos de gran timidez. El año 2014, la economía mundial observó un crecimiento de 2,6 por ciento y todo indica que el año 2015 será levemente superior al 3 por ciento. En los años siguientes mejorará apenas.

Los países desarrollados muestran un crecimiento diverso. Los Estados Unidos de América son los más dinámicos, seguidos parcialmente por el Reino Unido y algunos países nórdicos, en tanto que la zona Euro muestra una gran debilidad.

Los países en desarrollo, que habían tenido fuertes cifras de crecimiento en años anteriores, continúan desacelerándose si bien mantienen un nivel de crecimiento mucho más alto que los países desarrollados. Ellos se mantendrían en los próximos años en torno a un 4,5 por ciento de crecimiento anual. China cayó por debajo del 7 por ciento y se mantendrá los próximos años más cerca del 6 . La India, que en términos de paridad de poder de compra se ha convertido curiosamente en la tercera economía del mundo, crece y se situará por sobre el 7 por ciento en el futuro cercano.

Europa está lejos de un nivel mínimo de recuperación, proceso que se acompaña en muchos países con un disfuncionamiento de los sistemas políticos democráticos y de desafecciones hacia las instituciones clásicas de la democracia.

El crecimiento de formaciones populistas de distinto signo, cuya expresión más grave son los nacionalismos antieuropeos y xenófobos, aumentan de la mano del hecho que las formaciones democráticas clá-

${ }^{3}$ Las proyecciones utilizadas en este ensayo corresponden al Fondo Monetario Internacional, el Banco Mundial y CEPAL. Lo importante para la argumentación no son las cifras en sí, que varían cada vez que son revisadas, sino las tendencias que ellas marcan. 
sicas atraviesan crisis profundas y tardan en encontrar respuestas a la inquietud social. Salvo excepciones, surgen con mucha lentitud nuevos movimientos sociales progresistas y pro-europeos a la vez, y pocos de ellos adquieren una fuerte dimensión política.

Grandes países emergentes, que hasta hace poco parecían llamados a jugar un rol importante en los asuntos mundiales, han perdido brillo, como es el caso de Brasil, Sudáfrica y México, entre otros. Otros países de gran tamaño e influencia regional, como Irán y Turquía, están atrapados en el conflicto entre modernidad y fundamentalismo.

La ampliación geopolítica que representó la creación del G-20 después de la crisis del 2008 ha perdido audacia y urgencia en su propuesta para caminar hacia una nueva arquitectura financiera internacional.

Después de un destello de cambio, las viejas prácticas especulativas que nadan a gusto en una economía internacional desregulada vuelven por sus fueros y procuran impedir la puesta en práctica de acuerdos regulatorios.

Se han agravado los problemas en el Medio Oriente, donde la primavera árabe que provocó tanta ilusión, con la excepción de Túnez, que está bajo brutal y constante ataque, es hoy una promesa interrumpida e incluso revertida por autoritarismos militares, estados desconfigurados y guerras civiles de diversas intensidades. El Estado Islámico es más que una banda: tiene dirección militar heredada del viejo ejército Iraquí, medios financieros, armas y una visión política, que consiste en una utopía regresiva, horrible pero estructurada, que organiza territorio y que combate dentro y fuera de la región a través de actos terroristas sangrientos.

Es desde las costas libias que se embarca buena parte de los emigrados a Europa provenientes en su mayoría de África subsahariana y el Medio Oriente, huyendo de las guerras y del hambre a través de una Italia completamente sobrepasada. Otros lo hacen a través de los Balcanes.

Allí se genera la parte sur de los conflictos europeos. La parte norte está marcada por un conflicto larvado con Rusia, quien practica una democracia fantasmagórica y autoritaria y muestra una voluntad terca de recuperar un rol de potencia como en tiempos pasados, y al decir tiempos pasados me refiero tanto al periodo soviético como a la larga historia del zarismo. 
En Asia, donde la economía es lejos la más dinámica, no todo son buenas noticias. En el plano político, existe una carrera armamentista poco ruidosa pero efectiva, y renacen conflictos de hondas raíces históricas que envuelven a China y Japón, como también a otros países. En India, las voces nacionalistas se escuchan con fuerza, mientras el problema coreano parece interminable y peligroso.

Si bien el África subsahariana muestra cifras altas de crecimiento, que tienden a acercarse al 5 por ciento como promedio, presenta una realidad profundamente contradictoria, donde avances económicos y sociales en algunos países coexisten con conflictos armados en otros, al tiempo que Estados fallidos, hundidos en la miseria, la violencia y luchas étnicas y religiosas, dan origen a la forzosa emigración.

El intervencionismo neoconservador de Estados Unidos terminó provocando más desorden que orden. Ello ha hecho muy difícil el camino de la actual visión estratégica, más cercana al smart-power ${ }^{4}$ del Presidente Obama, que genera inhibiciones que en ocasiones aparecen como una cierta ausencia que sólo últimamente ha dado pasos esperanzadores, como los acuerdos con Cuba y el pacto con Irán.

Si bien Estados Unidos continúa y continuará teniendo por muchos años una primacía militar, científica y tecnológica, su situación política interna se ha vuelto mucho menos cohesionada, al tiempo que dependiente de sus conflictos internos entre los sectores más conservadores y los más liberales, lo que muchas veces tiende a paralizar el proceso de decisiones.

Este cuadro nos muestra un mundo muy lejano a la colaboración frente al riesgo compartido que pregonaba Ulrich Beck. ${ }^{5}$

La "acumulación civilizatoria" como base de un consenso en torno a prácticas compartidas, universalizadas no a través de principios doctrinarios sino a través de la experiencia histórica que incluye las prácticas democráticas y el respeto a las libertades individuales, no parecería primar en el horizonte, al menos por el momento, del actual desarrollo mundial. Más bien se han producido diversos impulsos autoritarios y fundamentalistas para quienes el pluralismo parece ser una mala palabra, como también tendencias nacionalistas que aceptan la moderniza-

${ }^{4}$ Joseph Nye, The Power to Lead (Nueva York: Oxford University Press, 2008).

${ }^{5}$ Ulrich Beck, World Risk Society (Cambridge, UK / Malden, MA: Polity Press / Blackwell Publisher, 1999). 
ción instrumental que conlleva la globalización pero que practican un identitarismo inamovible y guerrero, a la vez que aborrecen un cosmopolitismo diversificado.

\section{LAS TENDENCIAS LARGAS}

La realidad del corto plazo puede terminar prefigurando un futuro de fragmentación de no producirse algunos cambios dramáticos en la política mundial, que son difíciles de imaginar actualmente. Es cierto que podría haber una evolución positiva en el reforzamiento de Europa y sus valores, avances democráticos en América Latina e inesperadas sorpresas en Asia o en África. Pero serían eso, más sorpresas que tendencias en curso.

La construcción de una gobernanza global que permita evitar conflictos a partir de grandes pactos universales, así como la construcción de una nueva arquitectura financiera que limite las tendencias actuales de la economía global, se ven demasiado distantes.

Mientras tanto parecen establecerse dos fenómenos, sobre cuya existencia ha surgido cierto consenso entre los estudiosos del proceso de desarrollo. ${ }^{6}$

El primero es una tendencia a la convergencia en el crecimiento económico. Como lo señalábamos al comienzo, los países en desarrollo, pese a su desaceleración, crecen a un ritmo bastante más rápido que los países desarrollados y lo seguirán haciendo por muchos años hasta alcanzar una cierta convergencia.

Algunas regiones lo harán más rápido, como Asia, y quizás otras lo harán más lentamente, como África, pero todo indica que ese mundo del futuro, que crecerá económica y demográficamente a cifras más bajas, será más homogéneo, más convergente, más parecido entre sus componentes aunque no necesariamente más ordenado y pacífico.

Lo paradojal es una segunda tendencia que hasta hoy parece inevitable: el crecimiento de la divergencia al interior de las sociedades, tanto a nivel de acumulación del patrimonio como de la brecha de ingresos. $^{7}$

${ }^{6}$ Entre otros, Piketty, Le capital; Pierre Rosanvallon, La société des égaux (París: Seuil 2011).

${ }^{7}$ Piketty, Le capital; Rosanvallon, La société. 
Parecería ser un fenómeno que atraviesa todo el mundo en diversas proporciones. Es menor donde las regulaciones de acumulación intergeneracional de patrimonio son más severas y donde existen procesos redistributivos más avanzados que limitan y morigeran la brecha causada por los ingresos nominales.

La sociedad del conocimiento no ha disminuido esta tendencia sino que la ha ampliado a través de un aumento relativo de la retribución a las tareas de "análisis simbólico", 8 que son las más complejas, y una disminución relativa de la retribución a las tareas más rutinarias, que requieren menor calificación. Curiosamente la excepción en el aumento de la brecha distributiva en los últimos años fue América Latina, aun cuando en términos muy modestos, algo que coincidió con un periodo de bonanza económica que desgraciadamente ha concluido.

Claro, las tendencias no son un destino. Siempre los hombres pueden enderezar o torcer la historia para bien o para mal. Pero si las tendencias siguieran desarrollándose en el mismo sentido de hoy, el futuro sería el de un mundo cuyo crecimiento económico será muy cansino —quizás demasiado para los desafíos que debe enfrentar tanto sociales como naturales-; más convergente y al mismo tiempo más desigual; con un bajo, casi inexistente, nivel de gobernanza global; y donde valores como la democracia y las libertades individuales continuarían ausentes de los sistemas políticos de amplios e importantes territorios del planeta.

Esta visión, más realista que pesimista, no debe dejar de lado otros aspectos de la realidad, que pudiéramos llamar de modernización global y que dicen relación con los impactos sociales del avance del conocimiento, que contribuyen a mejorar el piso de la existencia humana, producto de la extensión a todos los países de nuevas tecnologías, y ayudan a aliviar las necesidades humanas básicas. Tampoco se puede menospreciar la extensión del conjunto de instrumentos de políticas públicas que generan, a nivel global, un mínimo "más humano y menos animalesco" de la vida humana.

\footnotetext{
${ }^{8}$ Robert Reich, The Work of Nations (Nueva York: Random House, 1992).

${ }^{9}$ Me refiero a la ausencia de progreso colectivo en la calidad de la vida de la enorme mayoría de personas que atraviesa toda la historia de la humanidad, hasta bien adentrada la sociedad industrial; aquello que magistralmente describió Thomas Hobbes en El Leviatán (1651), cuando señaló: "La vida del hombre es solitaria, pobre, animalesca, brutal y corta".
} 
En todo caso, no hay un destino trazado y no aparece en el horizonte ni la revolución mundial que imaginó Marx, ni la guerra de civilizaciones que predijo Huntington de manera más reciente. Pero es cierto que sabemos poco adónde vamos.

Aun así, es evidente la necesidad de un cambio, no para procurar alcanzar el mejor de los mundos, sino un mundo apenas mejor.

\section{AMÉRICA LATINA DESPUÉS DE LA BONANZA}

La bonanza terminó en América Latina. No fue corta, duró diez años.

Para encontrar un promedio de crecimiento similar es necesario retroceder a los años sesenta del siglo XX, en pleno corazón de los treinta gloriosos en su versión latinoamericana.

El promedio de crecimiento entre 2003 y 2013 fue en torno al 4,5 por ciento y fue capaz de soportar los efectos de la crisis del año 2008 teniendo una breve fase recesiva de un año para recuperarse con fuerza el año 2010.

La desaceleración comenzó a mostrar sus primeros efectos durante el año 2013 y se consolidó en 2014 y 2015. Tendrá probablemente una ligera recuperación en los próximos años.

Durante el periodo del crecimiento económico, considerando siempre las heterogeneidades conocidas en la región, su promedio superó el crecimiento mundial gracias a los altos precios de las materias primas, metales, productos agrícolas y carburantes; el aumento de los flujos financieros y de la inversión; una gestión macroeconómica razonable en la mayoría de los países y la presencia de nuevos grandes mercados como China y la India.

En este contexto, fueron más favorecidos los países sudamericanos que los de América Central y el Caribe, más ligados a la economía norteamericana, a la manufactura de baja tecnología y al turismo.

Durante esos años, la deuda pública disminuyó, las reservas aumentaron y los indicadores sociales fueron muy favorables.

La brecha de distribución del ingreso se acortó casi en todos los países de la región de una manera moderada aunque también significativa, ya que ha sido históricamente muy alta en la región y, junto a ello, esta brecha creció - y no poco- en el resto del mundo. 
La pobreza de la región era, en promedio, del 43,9 por ciento en el año 2002, mientras que la extrema pobreza era del 19,3. El año 2013 era del 28,1 por ciento y la extrema pobreza de 11,7 .

En ese periodo, alrededor de sesenta millones de personas salieron de la pobreza, vale decir alrededor del 10 por ciento de la población total de América Latina, y conformaron una nueva categoría social que se percibe a sí misma como clase media.

Se trata sobre todo de una percepción, porque concuerdo con Fernando Henrique Cardoso ${ }^{10}$ que ellos no constituyen verdaderamente una clase en sentido sociológico. Si bien salieron de la pobreza continúan en una situación frágil y precaria, están demasiado cerca todavía de la frontera con la pobreza y tienen con razón mucho temor de volver atrás.

Es verdad que ellos mejoraron su calidad de vida, que son más escolarizados, que tienen mejores accesos a servicios públicos, y que también, en algunos casos, tienen mejores trabajos, en ocasiones en el sector formal, y mejor remunerados. Pero también quisieran estar seguros de que ello constituye un piso a partir del cual solo se mejorará. La satisfacción de lo obtenido ya está en el pasado y su estado de ánimo es grunón vigilante, insatisfecho, crítico, y desconfía de los poderes políticos y económicos. Constituyen actores sociales sin una tradición de organización, pero conectados a las nuevas tecnologías, muy sensibles a los escándalos y actos corruptos que abundan entre quienes ejercen el poder o los poderes en la región. Sus aspiraciones han crecido y aspiran "a mucho, de todo y ahora".

Esas aspiraciones tenían una base de respuesta en los años del crecimiento. Hoy, cuando sus aspiraciones son más altas, la base de respuesta se ha restringido. En todos los países de la región el consumo tiende a bajar, las inversiones son más prudentes y los precios de las materias primas han caído en el mercado mundial, mientras que en varios de ellos se afloja la seriedad macroeconómica y los niveles inflacionarios aumentan.

La situación no es aún dramática: los niveles de empleo y salarios no presentan caídas bruscas y las adquisiciones sociales tienden a man-

${ }^{10}$ Fernando Henrique Cardoso, "América Latina en el mundo global", en Pensamiento global II, editado por Ernesto Ottone (Santiago: Universidad Diego Portales, 2012). 
tenerse, pero todo se hará más difícil en los años futuros de no producirse un cambio de tendencia que, aunque sea modesto, tenga alguna persistencia en el tiempo.

Sin embargo, las proyecciones económicas acerca del crecimiento económico muestran que no será fácil una inversión de tendencias o que, en el mejor de los casos, tomará su tiempo.

En el año 2015 el crecimiento económico de la región será de 0,5 por ciento para América Latina, en tanto que la subárea de América del Sur no crecerá. Argentina decrecerá más de medio punto; Brasil, de uno y medio, y Venezuela 7 puntos. Otros países, como Chile y México, crecerán seguramente menos de 2,5 por ciento y aquellos que estaban creciendo mucho, como Bolivia, Colombia y Perú, estarán bordeando el 4 por ciento o probablemente por debajo.

Si a ello agregamos que durante el periodo de bonanza poco se avanzó en las tareas estratégicas para un desarrollo más sostenible en el tiempo - esto es, en materia de educación, formación y transformación productiva en general-, y que esas tareas que no se hicieron en la abundancia deberán hacerse con más dificultades en una fase de restricciones, las presiones sobre la política serán muy fuertes, y gobiernos de orientación muy distinta vivirán bajo una presión social acrecentada durante los próximos años. Así habrá una fuerte centralidad de la política a nivel nacional, en un contexto regional y global difícil.

\section{LA CENTRALIDAD DE LA POLÍTICA Y EL SÍNDROME POPULISTA}

La década de bonanza fue curiosamente un periodo de gran diversificación política en la región. Ello había sido anticipado por la elección de Chávez en Venezuela en 1999.

Afortunadamente ese cambio de orientación se dio a través de procesos electorales pacíficos que produjeron cambios de tendencias en muchos países.

El primer decenio del siglo XX abrió paso a un amplio abanico político en la región: gobiernos de derecha, un número importante de gobiernos de centro izquierda y otros difíciles de clasificar como el kirchnerismo; sin embargo, la gran novedad, ruidosa en sí misma y amplificada tanto en la prensa mundial como en el análisis político, fueron los gobiernos autodenominados bolivarianos, encabezados por 
el chavismo venezolano bajo la bendición de una Cuba crepuscular y necesitada de petróleo.

Esa diversificación está muy ligada al mediocre comportamiento de las economías latinoamericanas y a la volatilidad de sus avances sociales en los años noventa, lo que provocó particularmente en los dos primeros años del siglo XXI una enorme frustración, y una crítica implacable a la conducción económica de esos años, marcada en diversa medida por la ortodoxia económica.

La única excepción fue la de Chile y, muy parcialmente, la de Brasil.

Esta frustración fue la madre tanto del que "se vayan todos" en Argentina como la del espacio de influencia de la fumosa doctrina bolivariana y del socialismo del siglo XXI, cuyo misterioso significado se llevó Chávez a la tumba.

Estos regímenes, que obtuvieron mayorías electorales en Bolivia, Ecuador y Nicaragua, fueron y son en el presente diferentes entre sí. Venezuela y Ecuador nacen del desmoronamiento de sistemas políticos democráticos, donde la corrupción y la venalidad se hicieron insoportables. Nicaragua obedece a una versión en farsa del sandinismo revolucionario, aliado a sectores conservadores que reemplazan vieja corrupción por nueva corrupción. Bolivia es un fenómeno mucho más profundo e interesante, pues el ascenso al poder de Evo Morales está marcado por la inclusión del movimiento indígena en un país donde ellos constituyen el 66 por ciento de la población.

En la gestión de esta experiencia es necesario distinguir un accionar que muchas veces muerde con disgusto el freno de las reglas democráticas y una retórica nacionalista y antinorteamericana, con un gobierno al mismo tiempo prudente en la gestión macroeconómica, dispuesto a acuerdos de carácter nacional y portador de desarrollo que combina un mayor rol estatal con economía de mercado.

Sin embargo, estos países tienen un peso limitado en la región, por el tamaño de sus economías y su nivel de desarrollo. Constituyen un porcentaje modesto de la realidad latinoamericana.

Sólo Venezuela tiene más peso, pero después de la muerte de Chávez y con la caída del precio del petróleo hoy es mucho más débil, y enfrenta una situación interna de polarización sin retorno en sus actuales parámetros políticos. Su capacidad de influencia es casi inexis- 
tente, lo que deja el proyecto bolivariano en una sobrevivencia difícil y sin capacidad de expansión.

¿Se pueden calificar estos regímenes de populistas, ya que revolucionarios o socialistas en sentido histórico no lo son? Depende de la definición que usemos para entenderlos. Pienso que no resulta muy útil un debate conceptual, en términos históricos o en las definiciones clásicas de las ciencias sociales. Me refiero a la elaboración de autores como Shills o Willis y, en el caso latinoamericano, las interpretaciones de lo popular nacional de Germani, Di Tella o Laclau.

Es más útil para el análisis de las realidades actuales considerar el populismo en un sentido muy amplio, como un síndrome más que como una doctrina. Por tanto, puede tener lugar en regímenes políticos muy diferentes, como una forma de ejercicio del poder que se refiere al "pueblo" como algo homogéneo, opuesto a la élite, a la idea de oligarquía y a los "poderosos", lo que va acompañado en el caso latinoamericano, la más de las veces, con una amalgama de los poderosos y los Estados Unidos de América, concebido este último como portador de un imperialismo perpetuo. En estos regímenes, los líderes carismáticos se fusionan directamente con el pueblo a través de una identidad emocional que tiene para ellos más valor que la institucionalidad democrática.

Los regímenes bolivarianos tienen en común esa aspiración de fusión con el pueblo, un origen electoral y pacífico, un antiimperialismo más retórico que real, la mantención de las instituciones democráticas - aunque sometidas a distintos niveles de rudeza, arbitrariedad y control autoritario-, una vaga y neblinosa ideología socialista, la voluntad de sus líderes de perpetuarse en el poder y una alianza fuerte con el estamento militar con la ayuda de un discurso nacionalista.

Algunos autores los han calificado de manera diversa, como neo jacobinos ${ }^{11}$, democracias delegativas ${ }^{12}$ o autoritarismo electivos ${ }^{13}$. Sea cual fuere su definición, todos poseen fuertemente el síndrome populista, aunque el síndrome populista no es monopolio sólo de ellos.

${ }^{11}$ Ernesto Ottone, "Izquierdas, centro izquierdas y progresismos en América Latina hoy: Algunas distinciones”, Estudios Públicos 118 (2010): 315-32.

12 Guillermo O'Donnell, "Delegative Democracy", Journal of Democracy 5, n. ${ }^{\circ} 1$ (1994): 55-69.

${ }^{13}$ Michelangelo Bovero, "Las condiciones de la democracia. Una teoría neobobbiana", en Pensamiento global II, editado por Ernesto Ottone (Santiago: Universidad Diego Portales, 2012). 
Rasgos de ese populismo los podemos encontrar por de pronto en el peronismo, particularmente en su versión kirchnerista, en sectores de la izquierda que forman parte o están en la periferia de los gobiernos de centro izquierda de Chile, Brasil y Uruguay, y por supuesto a la izquierda de la izquierda.

Pero el síndrome populista no tiene su domicilio sólo en la izquierda latinoamericana. Elementos populistas se pueden encontrar en el nacionalismo peruano, en la derecha colombiana - sobre todo en la versión uribista- y en México, donde su larga tradición populista deja huellas en todo el espectro político.

Sin embargo, la lluvia del bajo crecimiento y de un negativo entorno global, alcanzará a todos los gobiernos. Sea cual sea el tamaño de su síndrome populista, todos quedarán mojados. Los más sólidos económica y políticamente se protegerán mejor. Todos ellos están sufriendo fenómenos similares. Los gobiernos actuales tienden a perder apoyo popular. Los líderes más carismáticos lo hacen más lentamente, pero sus partidos son castigados, incluso inesperadamente. El caso más notable es la derrota del MAS de Bolivia en El Alto, ciudad simbólica del movimiento indígena, donde triunfó en las elecciones municipales una dirigente aymara pero de derecha.

Las causas están ligadas a la caída económica, a casos frecuentes de corrupción y, en algunos casos, a las violaciones de las reglas democráticas y el crecimiento de la violencia criminal asociada al narcotráfico, que penetra el sistema político.

Pero el problema es más grave, pues comienza a desarrollarse una falta de apoyo al sistema político democrático y altos grados de escepticismo y desconfianza a las instituciones clásicas del sistema, a los políticos y la política.

Por cierto, no se está aún en una situación dramática, no existe una guerra fría que dé alas a golpes de Estado militares. Dictaduras como en los años setenta del siglo pasado no están en el horizonte, como tampoco nuevas guerras civiles de carácter ideológico. Por el contrario, los pasos de acercamiento entre Estados Unidos y Cuba le ponen la lápida final a toda esa época, y también el proceso de búsqueda de paz en Colombia contribuirá si logra concretarse.

En este cuadro, y con un crecimiento económico moderado, no se puede seguir postergando la necesaria transformación productiva de la 
región, una que le permita una inserción en la economía global menos dependiente de los vaivenes de los precios de los productos primarios y posea un dinamismo económico diversificado, capaz de incorporar conocimiento, saber hacer y productividad que asegure una inserción más autónoma y sustentable en la economía global.

Tampoco se puede permitir que la brecha de desigualdad pierda sus modestos avances, y menos que la pobreza empiece a crecer nuevamente. Para ello se requerirá más que en el pasado un mejoramiento muy importante de la calidad de la política, una reforma profunda de los estándares éticos de las reglas que ordenan el sistema político, y partidos políticos renovados, capaces de dialogar con los movimientos sociales ordenando y priorizando sus demandas.

Si los sistemas democráticos y los dirigentes que allí ejercen el poder son incapaces de construir esas respuestas, en vez de disminuir el síndrome populista, cuyo lenguaje puede partir tanto del discurso del orden como del cambio, se podrá producir la aparición de líderes carismáticos, decididos a gobernar con métodos plebiscitarios y autoritarios, reduciendo al mínimo la institucionalidad democrática.

Si eso sucede, América Latina habrá frustrado una vez más la posibilidad de lograr un desarrollo más democrático y más igualitario a la vez, y las duras lecciones del pasado no habrán sido aprovechadas en la construcción de un futuro deseable. EP 